\title{
Lovisa Bergdahl \\ Crisis or Struggle? \\ A Language of Natality as a Struggle for Education
}

\begin{abstract}
Taking its point of departure in the connotations to war and violence inherent in what is here called the Ianguage of crisis' (Jantzen), the purpose of this article is to explore what it might mean to reassess the language of educational change and policy reform in the imagery of natality and birth (Arendt). If the task in a 'crisis' is to fight against the crisis, effectively and forcefully, the argument of the paper is that the root metaphors of natality and birth puts into play an imagery that makes possible a relational language for educational change and reform. If the language we use has performative consequences, the question explored is what a 'language of natality' can make possible as a language of struggle for education.
\end{abstract}

\section{Keywords}

natality, birth, mortality, policy reform, change

\section{Introduction: The Language of Crisis}

Education is in crisis, according to public discourse, and in many Western countries we regularly wake up to new alarms. In Swedish daily papers, to take an example, 'getting into teacher education demands less than a randomly answered university test'; 'results in math's are reaching a new low'; 'thirteen of nineteen schools fail in their work against bullying', and 'lack of discipline and order in schools' are only some the most recent headlines. Getting out of the current crises will be a 'battle', it continues, and if anything is going to change in the current situation we will have to 'fight bad results', 'declare war against the lack of order and discipline' and 'forcefully combat all kinds of discrimination'. As a direct consequence of this 'language of crisis', education is debated by well-nigh anyone: it is as if the 'crisis' has given a green light to politicians to initiate yet another reform and for a wide range of professionals - economists, communication strategists, neuropsychologists, journalists, just to mention a few - to discuss education without having neither theoretical nor professional knowledge about the field.

The 'language of crisis', however, concerns not only education and the article takes as its starting-point the idea that the concept of 'crisis' is part of a violent and masculine rhetoric that is being used in everyday socio-political discourse to draw attention to, and to make sense of, all kinds of different failures. In this sense, the article sees the 'langue of

Lovisa Bergdahl, Södertörn University, Sweden

e-mail: lovisa.bergdahl@sh.se

Studier i Predagogisk Filosofi | https://tidsskrift.dk/spf/index | ISSN nr. 22449140 
crisis' as part of a patriarchal framework and while it would be tempting to believe that the masculine rhetoric of 'crisis' has a recent origin, everyday discourse has been saturated by metaphors of violence, war, and death throughout Western history. ${ }^{1}$ From modernity and onwards, however, as late philosopher Graze Jantzen has pointed out, such metaphors were given new proportions and since then a discourse on war and violence has been used even in relation to aspects of life where such metaphors should have no place. ${ }^{2}$ As a consequence of this, we are 'fighting cancer', 'battling child abuse' and 'issuing war against homelessness' - even a good philosophical debate or discussion is often framed in terms of a 'battle', as in 'let the better argument win'.

The way out of the crisis in education, the less alarmist voices say, is to focus more on the future and what the future can bring in terms of political stability, jobs and economic independence. What is needed, in other words, is a focus on what comes after education and the consequence of this, as scholars in philosophy of education have critically pointed out, is an undermining of education, reducing it into merely an instrument for safeguarding either the future of democracy and/or the future of the market. ${ }^{4}$ In this sense, the language of crisis works against education, reducing education to being about 'making a living' instead of also being about 'making a life' - a distinction used by Säfström and Månsson in order to illustrate how the marketization of schools has shifted the governing idea of education from being about critical thinking, community building, and emancipation to producing well-functioning workers for the job market. ${ }^{5}$

What I wish to highlight in the above, as a point of departure, is necessarily in broad brush strokes and quite programmatic: the 'language of crisis' used to motivate change and policy reform in education today draws on a whole arsenal (sic!) of images and metaphors related to war and violence that has devastating effects on education, both on structural and personal level. The assumption is that the 'language of crisis' legitimizes politicians to pull into schools with 'heavy artillery', initiating by force yet another far-reaching policy

1 Grace Jantzen, Becoming Divine. Towards a feminist philosophy of religion. (Manchester: Manchester University Press 1998).

2 Grace Jantzen, "Flourishing: Towards and ethic of natality". Feminist Theory, (Vol. 2(2), 2001), 219-232, https://doi. org/10.1177/14647000122229497.

3 Jantzen, "Flourishing: Towards and ethic of natality", 228.

4 In recent years, a vast number of researchers in philosophy of education have been discussing the absurdity of a situation where, despite the fact that the future is more unpredictable than ever and clearly beyond our control, education keeps being motivated with precisely this: the future. A key text in this regard is Gert J.J. Biestas, Beyond learning: democratic education for a human future, Boulder: Paradigm Publishers, 2006). For critique of the marketization of the school, see Gert J.J. Biesta, Good education in an age of measurement: ethics, politics, democracy, (London: Routledge, 2016); and Carl Anders Säfström and Niclas Månsson, "The Ontology of Learning, or Teaching the Non-Person to Learn" in INTERACÇÕES, (No. 37, 2015), pp. 66-82. For another powerful critique of the marketization of the school and for offering a now widely discussed counter image of what the school might become, drawing on the Greek notion of scholè, see Jan Masschelein and Maarten Simons's In Defence of the School: A Public Issue (Leuven: E-ducation, Culture \& Society Publishers, 2013).

5 Säfström \& Månsson, "The Ontology of Learning, or Teaching the Non-Person to Learn", 74. 
reform. ${ }^{6}$ Given this background, the main purpose of the paper is to explore what it might mean to reassess the language for educational change and policy reform in the root metaphors of natality and birth, metaphors that seem to generate what this paper chooses to call a language of struggle for education. If the 'language of crisis' connotes to war and violence and generates an approach to educational reform where the main task is to fight against the current ills of education quickly, effectively, and forcefully, it is central to the argument that natality and birth can offer an approach to educational change and reform that involves a struggle for education. There is much nuancing to be done here, but if the language we use has performative consequences and both reflects and impacts upon our material realities, ${ }^{8}$ the more precise question is what a language of natality and birth can make possible as a language of struggle for education.?

The paper is divided into three parts. The first part offers a feminist philosophical context to the 'language of crisis', reading its focus on immortality and on the future as a patriarchal regime that has its roots in a linear understanding of time. Time is also what is in focus in Arendt's famous essay 'The Crisis in Education' and the second part of the paper explores what natality and birth, read as notions of time, can offer a language of struggle for education. It is suggested that they; a) interrupt death by interrupting both linear and cyclical time, and; b) alters the relationship between immortality and mortality. The argument is that 'the language of natality' puts into play an imaginary that makes possible a relational language for educational change and reform. The contribution of the paper is to show what this relationality involves and it is suggested that it not primarily offers a counter-image to 'the language crisis', but an approach to educational change and reform that acknowledges both continuation and change, both the old and the new, both the past and the future. Hence, the third part of the paper offers three aspects on how Arendt's thinking on natality and birth can make a difference to policy reform in education.

6 It should perhaps be mentioned here that the last decade in Swedish education is being talked about as the most 'reform dense' period in recent history and that Swedish teachers are suffering from 'reform fatigue'.

7 I owe the playful distinction between crisis and struggle to Marie Hållander, PhD, one of the guest editors of this special issue. It might be worth pointing out that the discrepancy between 'fighting against' and 'struggling for' is a bit clearer in the Swedish and German languages than in the English language. Whereas a crisis [Sw. kris; Ge. krise] is often articulated in the negative and is expected to give rise to 'counter action' or 'defence', a struggle [Sw. kamp; Ge. kämpfen], by contrast, is usually articulated affirmatively, as a struggle for something. This is why the paper articulates the 'language of natality' as an affirmative struggle for education.

8 Judith Butler, Excitable Speech: A Politics of the Performative. (New York: Routledge 1997).

9 Quite a lot of research has been done on Arendt's notion of natality, both within philosophy in general and in philosophy of education. In philosophy of education, see, for example; Mordechai Gordon, "Hannah Arendt on Authority: Conservatism in Education Reconsidered" in Hannah Arendt and Education: Renewing our Common World (edited by Mordechai Gordon), (Boulder, Colorado: Westview, 2001); Natasha Levinson, "The Paradox of Natality", in Hannah Arendt and Education: Renewing our Common World (edited by Mordechai Gordon), (Boulder, Colorado: Westview, 2001); Natasha Levinson, "A 'More General Crisis': Hannah Arendt, World-Alienation, and the Challenges of Teaching for the World As It Is", in Teachers College Record (Vol. 112, No 2, 2010), 464-487. In philosophy in general, see, among many; Grace Jantzen, Violence to Eternity, (edited by Jeremy Carrette and Morny Joy), (London: Routledge 2009); Grace Jantzen, "Flourishing: Towards and ethic of natality". Feminist Theory, (Vol. 2(2), 2001), 219-232; Patricia Bowen-Moore, Hannah Arendt's Philosophy of Natality" (Basingstoke: Macmillan, 1989). 


\section{Feminist Philosophy and the 'Language of Crisis'}

According to feminist philosophers, the philosophical tradition of the West has been preoccupied with death and violence already since Homer and Plato. ${ }^{10}$ Paradoxically, however, the preoccupation with death is spurred on by its opposite, Grace Jantzen argues, that is, by an almost obsessive like focus on avoiding death and striving for immortality. ${ }^{11}$ This focus on avoiding death and attaining immortality is related to the notion of time, and it has taken shape and form in a patriarchal order defined by an exaggerated focus on the 'otherworldly': either on life after death or on life before birth or, simply, life in other worlds. Luce Irigaray captures this 'otherworldly' focus in patriarchy, when she writes:

\footnotetext{
"The patriarchal order is based upon worlds of the beyond: worlds of before birth and especially of the afterlife, other planets to be discovered and exploited for survival, etc. It doesn't appreciate the real value of the world we have and draws up its often bankrupt blueprints in the basis of hypothetical worlds."12
}

Generally speaking then, Western discourse has generated an imaginary that in its obsessive focus on immortality and 'worlds beyond' disregards life in this world - life in the present, in the concrete and material place of the here and now - emphasizing instead the (ideal) future and trying to attain control over the future. This emphasis on the future and its simultaneous disregard for the present (as well as for place and materiality), feminist philosophers argue, has had devastating effects not only on the lives of women but also on the material and physical world more generally. One could in fact argue that there is a direct relationship between the exploitation of women's physical bodies and the exploitation of the earth, suggesting, as pointed out by the Swedish journalist Björn Wiman in the Swedish daily Dagens Nyheter recently, that the exploitation of the world's natural resources and the exploitation of the female body are two sides of the same coin. ${ }^{13}$

The patriarchal order with its focus on immortality and its dismissal of life in the present has ancient roots but it reaches its most disturbing peak in modernity, Jantzen argues, erupting in what she calls 'a masculinist drive for mastery'.14 This idea was meant to be the theme of a planned six-volume work on Western philosophy, Death and the Displacement of Beauty, but only the first volume was completed before she died. In one of her earlier books, Becoming Divine, she develops a feminist philosophy of religion and it is here that

10 Two of the most explicit thinkers in this regard are Grace Jantzen, Becoming Divine. Towards a feminist philosophy of religion. (Manchester: Manchester University Press 1998); and Luce Irigaray, An Ethics of Sexual Difference. (London: The Athlone Press. 1993).

11 Grace Jantzen, Becoming Divine. Towards a feminist philosophy of religion; Grace Jantzen, "Flourishing: Towards and ethic of natality".

12 Luce Irigaray. Je, tu, nous: Toward a Culture of Difference. (London: Routledge. 1993), 27.

13 https://www.dn.se/kultur-noje/kronikor/bjorn-wiman-den-nya-kvinnororelsen-visar-att-allt-kan-forandras-narman-minst-anar-det/ [accessed 2018-02-02].

14 Janzen, Becoming Divine, 129. 
she describes the imaginary of modernity as a violent and 'death-dealing' habitus characterizing especially the twenty-first century. She writes:

\begin{abstract}
"From militarization and death camp and genocide to exploitation and commodification and accumulation of wealth; from the construction of pleasure and desire to the development of terminator genes; from the violence on the streets to the heaven-obsessed hymnody of evangelical churches: preoccupation of death and the means of death and deathly combat is ubiquitous. It is a necrophilia so deeply part of the western habitus that it emerges at every turn."15
\end{abstract}

The striving for immortality and the disregard for life in the present in modernity also comes in a religious variant. ${ }^{16}$ The focus on what in certain religious traditions was referred to as "eternal life" was in the advent of modernity transformed and inverted into a pietistic focus on living a vigorous life here and now, coming to the fore - in combination with the rise of the industrial, modern society - as a focus on productivity, prosperity and progress. ${ }^{17}$ Heaven on earth was to be implemented in this life or, more precisely, life in the present was used as a means to reach the final goal, which was the future, or the life hereafter. There is not enough space to go into this religious variant in much detail here. The point I wish to make is simply that it seems as if the focus on the future and on immortality in modernity, or the urgency to escape mortality by focusing on controlling the future, in both its' secular and religious variants has led to its paradoxical opposite. In other words, it seems as if the unbridled focus in modernity on the (better) future and the (illusory) belief in the immortality of man has generated a crisis-driven and violent approach to the present, onto which man has sought to project an already thought-out and planned future. It is, simply put, as if a one-sided focus on immortality and the future, in both its secular and religious variants, has led to its opposite: the loss of a (real) future, replacing the arrival of the new and unforeseen with old projections.

In her article "Revolutionary Time: Revolt as Temporary Return", Fanny Söderbäck argues that time is 'the frame through which we are able to articulate both continuity and discontinuity' and she returns us to the classical distinction between linear and cyclical time..$^{18}$ Men, she argues, have often laid claim to linear time, taking upon themselves to subordinate nature and the body to culture and reason, whereas women have been relegated to the natural realm and to the body and, hence, women have been the bearers of cyclical time. ${ }^{19}$ This classical distinction has been the basis for the division of labour throughout

15 Janzen, "Flourishing", 228.

16 See Janzen, Becoming Divine and Charles Taylor, A Secular Age, (Cambridge, Mass.: Belknap Press of Harvard University Press, 2007).

17 Janzen, Becoming Divine, 137-141.

18 Fanny Söderbäck, "Revolutionary Time: Revolt as Temporary Return" in Signs: Journal of Women in Culture and Society, (2012, vol. 37, no. 2, 301-324), 303, https://doi.org/10.1086/661710.

19 Fanny Söderbäck, "Revolutionary Time: Revolt as Temporary Return", 301. 
modernity, and whereas it has associated men with a linear paradigm of progress and prosperity and to transcendence, culture, and reason, it has associated women with a cyclical paradigm of return and repetition and to immanence, nature, and body..$^{20}$ According to Söderbäck, both linear time and cyclical time belong to the regime of patriarchy, because, if linear time tends to forget the past and in this forgetfulness fails to ground us in history in a way that provides us with continuity - cyclical time tends only to repeat the past and, hence, does not allow for change. In this sense, Söderbäck writes, 'neither linear time nor cyclical time carries true potential for liberation and change.2. What is needed by contrast, she concludes, is a notion of time that allows for both continuation and change. A temporal movement, she writes, 'that neither forgets nor repeats the past, a model of time that allows us to redeem the past and the present without instrumentalizing them in the name of a future always already defined in advance.'.22

Söderbäck finds resources for such a notion of time in Julia Kristeva's work, but for our purposes here let us turn to Hannah Arendt and explore how time operates in her notions of natality and birth. If the 'language of crisis' according to feminist philosophy is characterized by both a violent approach to change and reform due to its obsession with the future and the linear-progressive paradigm, and by a violent approach to the world and life in the present due to its desire to escape mortality and create immortality - what can natality and birth offer as another way of speaking and thinking about educational reform? Let us in the following explore how Arendt's notions, according to the reading that I do of her work here, a) interrupts death by interrupting both linear and cyclical time, and; b) alters the relationship between immortality and mortality.

\section{Arendt's 'Crisis', Natality and Birth}

In an article that takes issue with the notion of crisis, it might seem strange to foreground a text in which 'the crisis' appears already in the title. We should not be misled by the title, however, because Arendt begins her essay 'The Crisis in Education'23 by elaborating on the notion of 'crisis' itself. In fact, the crisis only turns into a disaster, she argues, if we let it prevent us from thinking and if we - instead of 'running the risk of failure ${ }^{24}$ - respond to the questions it rises with a fait accompli, that is, 'as though the new already existed'. ${ }^{25}$ The main risk in a crisis, in other words, is that we pretend that change is already in place and that we respond to difficult questions with readymade answers. ${ }^{26}$ Hence, 'the crisis' can create pos-

20 Fanny Söderbäck, "Revolutionary Time: Revolt as Temporary Return", 303.

21 Fanny Söderbäck, "Revolutionary Time: Revolt as Temporary Return", 308.

22 Fanny Söderbäck, "Revolutionary Time: Revolt as Temporary Return", 304.

23 Hannah Arendt, "The Crisis in Education". Between Past and Future. (New York: Penguin Books.1961/1993).

24 Arendt, "The Crisis", 176.

25 Arendt, "The Crisis", 176-177.

26 Arendt, "The Crisis", 174. 
sibilities for change if we do not pretend that the solutions are already there. ${ }^{27}$ In this sense, educational reform is always about taking risks and about carefully navigating towards an unknown and unpredictable future.

\section{a. Natality and Birth: interrupting linear and cyclical time}

Arendt's notion of natality is inspired by Saint Augustine and his idea that human beings, by virtue of being created as new beginnings, can themselves create new beginnings. ${ }^{28}$ This ability to begin, she writes, 'is guaranteed by each new birth; it is indeed every man'.29 and with this ability to begin, comes the possibility for changing the given course of things (as beginners). Hence, at the centre of the notion of natality lies a potentiality for initiating change that each of us brings to the world by virtue of our own birth.

In Arendt's thinking, our factual and physical birth into the world is used as a root metaphor for the notion of natality. In comparison to our physical birth, natality represents a second birth ultimately linked to our ability for speech and action in the polis. ${ }^{30}$ With the capacity to begin comes the capacity for changing the given course of things (as beginners). Hence, at the centre of the notion of natality lies a potentiality for action that each of us brings to the world by virtue of our own birth, of being natals. It is this ability to insert new beginnings in the midst of an old world that 'looks like a miracle', Arendt writes, and saves the world from ruin. ${ }^{31}$ She continues: 'The miracle that saves the world, the realm of human affairs, from its normal, "natural" ruin is ultimately the fact of natality ${ }^{32}$ and because people are born, they can themselves 'give birth' and create newness.

What the notions of natality and birth suggest, is that if human beings were left to themselves, 'human affairs can only follow the law of mortality. ${ }^{33}$ But, because people are born, they can themselves 'give birth' and create new beginnings. ${ }^{34}$ Hence, natality and birth has the capacity to interrupt linear time. ${ }^{35}$ She writes:

27 Arendt, "The Crisis", 174.

28 Hannah Arendt, Love and Saint Augustine. (Chicago: The University of Chicago Press 1929/1996) but the inspiration is from Augustine's City of God [De Civitate Dei], book XII Ch. 20 (Translated by Henry Bettenson, St. Ives: Clays Ltd, 2003).

29 Hannah Arendt. The Origins of Totalitarianism. (New York: Schocken Books 1948/2004), 616. I am using 'man' and 'him' here in an inclusive sense, as referring to mankind and to both men and women.

30 In two of her main political works, The Human Condition and The Origins of Totalitarianism, natality is discussed as a political concept although in 'The Crisis in Education' natality is also the essence of education. Hence, natality is central to both to her political and to her educational work, although she clearly argues that these two realms should strictly be kept apart. The paper acknowledges this inconsistency in her thinking but it neither seeks to resolve it nor explore it further.

31 Hannah Arendt. The Human Condition. Chicago: The University of Chicago Press 1998), 246.

32 Arendt, The Human Condition, 247. It is important to point out in this context that 'the world' for Arendt does not refer to the natural world of trees and animals but to the traces of human words and deeds (speech and action) in the polis.

33 Arendt, The Human Condition, 246.

34 Arendt, The Human Condition, 246.

35 Arendt, The Human Condition, 246. 
"The life span of man running towards death would inevitably carry everything human to ruin and destruction if it were not for the faculty of interrupting it and beginning something new, a faculty which is inherent in action like an ever-present reminder that men, though they must die, are not born in order to die but in order to begin." 36

What is interesting about this well-known citation from Arendt's The Human Condition, Adriana Cavarero points out, is that Arendt here reverses the linear lifespan that in Western metaphysics runs from birth to death, suggesting instead that the notion of natality as a political category offers us a pattern that runs from death to birth. ${ }^{37}$ In other words, in beginning something new ruin and destruction is interrupted and renewal and restoration is moving towards us. Since death is the inevitable endpoint for everything and everyone that is alive (i.e. death is our ontological destiny), it is birth that Arendt takes as her central category for initiating change. By doing so, Cavarero argues, Arendt not only replaces one linear model with another linear model or simply substitutes birth to death as the preferred philosophical category - she actually also changes the pattern. ${ }^{38}$ By making birth the horizon towards which life is heading, the pattern Arendt calls our attention to is that birth is more than the starting-point for simply another linear model of time, it is the startingpoint, Cavarero writes, for 'a journey whose itinerary is not yet identified'. ${ }^{39}$ Hence, by reversing the perspective in this way, we (the old generation) are on a journey together with the new (the beginner and the beginnings) that cannot be foreseen or predicted.

Is it the case, then, that the interruption of linear time suggested above returns us to the cyclical model of time that was immensely popular in Antiquity? Birth and natality easily and naturally push us in this direction, Cavarero continues, ${ }^{40}$ but in contrast to the natural circle that in Antiquity was used to symbolize immortal life and the living-on of successive generations, 'man's life span ... looks like a peculiar deviation.' ${ }^{41}$

If we return to Arendt's work we see that what characterizes man's life span is a 'rectilinear movement $\mathrm{t}^{1 / 2}$ - a geometrical pattern that neither moves forward according to a linear pattern from birth to death (linear time), nor according to a circular movement that moves from birth to death and back into rebirth. No, since natality is the capacity to begin and since man himself is a 'beginning of a beginning', as Arendt puts it, ${ }^{43}$ - what characterizes the human condition is that man is inserted into time. ' $[1] \mathrm{t}$ is this insertion', Arendt writes, 'which splits up the time continuum into forces which then, because they are focused on the particle or body that gives them their direction, begin fighting with each other and

36 Arendt, The Human Condition, 246.

37 Adriana Cavarero, Inclinations. A Critique of Rectitude. (Stanford: Stanford University Press, 2016).

38 Cavarero, Inclinations, 111.

39 Cavarero, Inclinations, 111.

40 Cavarero, Inclinations, 111.

41 Arendt, The Human Condition, 246 in Cavarero, Incliations, 111.

42 Arendt, The Human Condition, 246.

43 Hannah Arendt, "Preface". Between Past and Future. (New York: Penguin Books.1961/1993), 11. 
acting upon man'.44 What Arendt offers in her notions of natality and birth, then, according to Cavarero, is a notion of time that breaks with both the linear and the circular patterns. She writes:

\begin{abstract}
"In other words, if we confront the ancient figure of the circle with natality instead of with mortality, beginning comes to the foreground and, by breaking down the circularity of natural movement, resoundingly interrupts it. Thus it is that the newborn breaks out of the circle, together with the human faculty that corresponds to it and that actualizes its disruptive force - namely, action."145
\end{abstract}

The first aspect that the notions of natality and birth bring to the fore then, is that they make change possible by interrupting both linear and cyclical time. The possibility for beginning something new and interrupt the given course of things is what saves the world from the path that runs quickly and straight to ruin.

\title{
b. Natality and Birth: mortal man - immortal world
}

Arendt's notions of natality and birth not only alters the relationship between death and birth and interrupts both linear and cyclical time, it also shifts mortality and immortality around. If modern life has come to build upon the (illusory) idea that the human can become immortal by leaving traces in the world (i.e. the emphasis on power, prosperity and progress in modernity), Arendt makes it clear that it is the opposite that is true: since we are born into a world that existed long before we made our entry into it and that will continue to exist long after we are gone, it is the world that is permanent and immortal and not the human being. However, natality and mortality should not be seen as exclusive to one another because mortality is 'the hallmark of human existence'. ${ }^{46}$ In fact, it is only as a mortal, with the capacity for enacting freedom, that man can create new beginnings. What Arendt helps us see is thus that although we are born to begin, it is not man that is immortal and permanent but the world - it is the world that will over-live us and be passed on to the coming generation.

Modern life, however, according to Arendt, is characterized by the precise opposite of this: we have come to believe that we ourselves are immortal whereas the world will perish. The victory of the philosopher's exit from the world, seeking the experience of the eternal and unchanging over and above the concerns of a life in the polis has, since the myth of the cave in Plato's The Republic, come to prioritize bios theoretikos over bios politikos and vita contemplativa over vita activa. ${ }^{47}$ The victory of the striving for the eternal and unchanging does not, however, only have philosophical roots. The fall of the Roman Empire demon-

44 Hannah Arendt, "Preface", 11.

45 Cavarero, Inclinations, 111-112.

46 Arendt, The Human Condition, 18.

47 Arendt, The Human Condition. 
strated the impermanence of the work of mortal hands and also did the Christian gospel's focus on eternal life for each individual contribute to making any striving for the permanence of the world futile and unnecessary. ${ }^{48}$ Hence, modern life cultivates an indifference to the world despite its activism - a kind of wordlessness - given further emphasis, as we saw with Jantzen earlier, in the puritan idea of a good life being rewarded in the hereafter. ${ }^{49}$

What is important to note here is that whereas the 'language of crisis' is motivated by the idea that man is immortal but that the world will perish and that man, therefore, can use the world as a means to his own ends, the notion of natality builds on the insight that the world is immortal and that man will perish. In this sense, the notion of natality not only shifts mortality and immortality around, it also reminds us of the immortal and performative character of our words and deeds and the importance of language. ${ }^{50}$ What natality rejects, then, is the anthropocentric belief that the world is a temporary arena we can use for our own purposes, reminding us that the world will over-live each human being's temporal existence.

The second idea that the notion of natality brings to the fore then is that it shifts mortality and immortality around, suggesting on the one hand that the world is immortal and that man with perish but on the other that although we are mortal, we are born to begin. Hence, we are neither born to die nor to (ab)use the world as a means to our own ends but to insert newness into the world.

\section{Rethinking Educational Policy Reform}

Given that natality is about beginning, could it not be argued at this point that the many policy reforms that are enforced upon education today are 'new beginnings'? Could it not be argued, therefore, that the last decade in for example a country like Sweden - which has been the most reform dense decade in its modern history - generates more 'beginnings' than ever? We must not forget, however, that an increasing number of teachers today describe their situation in schools as being characterized by having no choice. In my job as a teacher educator, I meet both teachers and teacher students who express frustration over their job situation because, as they often put it, 'there is no room for doing anything beyond what we must do - there is no room for creativity.' The question is then, how can we tell an educational reform generated by the 'language of crisis' from one generated from 'the language of natality'? Or, more correctly: what might policy reforms in education have to acknowledge if they were not to foreclose the possibilities for creativity and change? Let us look at three aspects on how natality and birth can make a difference to policy reform in education.

48 Arendt, The Human Condition, 21.

49 Arendt, The Human Condition, 16; 54.

50 See Butler, Excitable Speech. 


\section{a. Educational reform as temporary interruption}

According to Masschelein and Simons, education is the 'free time' for study that we insert between the sphere of the home and the agora (the public sphere) (e.g. the Greek idea of scholè)..$^{51}$ The 'free time' of the school is thus the 'space-time' that makes it possible to break with linear time and although what is being taught at school is necessarily oriented towards the past, the school as 'free time' between the past and future suspends the pre-determination and one-sidedness that comes with both a conservative and a progressive approach where the former tends to focus only on the past and the latter only on the future. ${ }^{52}$ The school, as Masschelein \& Simons put it, makes free time possible:

\footnotetext{
"insofar as it succeeds in temporarily suspending or deferring the past and the future, thus creating a breach in linear time. Linear time is the time of cause and effect: 'You are this, so you have to do that', 'you can do this, so you go here', 'you will need this later in later in life, so this is the right choice and that is the proper subject matter. Breaking through this time and logic comes down to this: the school draws young people into the present tense ... and frees them both of the potential burden of their past and of the potential pressure of a mappedout (or already lost) intended future." 53
}

For our purposes here, the temporary suspension of the past and the future in school creates an important break in time that gives education back, so to speak, to the new generation. In breaking with linear time, the pre-determined purposes of the school, projected onto it through an already defined future (as in, saving the future, the economy, the planet, democracy etc.) are also broken with. Given the school's in-betweenness in time, 'between the past and the future' to speak with Arendt, education is neither about a conservative repetition of the past, nor about an unrestrained focus on the future and an anxious and death-driven invention of the new. Rather, education is about temporarily interrupting time, so as to make possible a space in the present for studying the world.

What educational reform needs to consider then, if it does not want to simply reproduce the violent logic of the crisis, is to take seriously both continuation and change. Hence, instead of only using education as a projection screen for implementing an already defined idea of the future, educational reform needs to take into its concern a respect for what is already there, navigating carefully between the past and the future in the present, protecting both the old and the new. This is the only way that the next generation of educational reformers can interrupt the disastrous crisis in education and truly create something new.

51 Masschelein \& Simons, In Defence.

52 For further elaboration on the one-sidedness of both the conservative and the progressive position, see Lovisa Bergdahl and Elisabet Langmann, "Time for Values: Responding Educationally to the Call from the Past", in Studies in Philosophy and Education, (2017), https://doi.org/10.1007/s11217-017-9591-2.

53 Masschelein \& Simons, In Defence, 36 


\section{b. Educational reform as relational consideration}

Since the new (the child) is born into an old (pre-existing) world - a world that was there long before the new was born - the old needs to be protected from the damage (death) caused by the entry of the new, just as the new (birth) needs to be protected and cared for so that its newness is not destroyed (killed) by the old. In her advocating of this double responsibility, Arendt writes these much cited words:

\footnotetext{
"Education is ... where we decide whether we love our children enough not to expel them from our world and leave them to their own devices, nor to strike from their hands their chance of undertaking something new, something unforeseen by us, but to prepare them in advance for the task of renewing a common world." ${ }^{154}$
}

Thus, the double gesture of the protection and care of both the new and the old comes together in education, and the tension between them is always a matter of risk and negotiation.

This leads us to the second aspect of 'the crisis' that Arendt draws our attention to in her essay on education which is that we tend to use education and our children as a tool for building a new world. ${ }^{55}$ The relationship between the old world and the new generation is important here and although ' $[\mathrm{i}] \mathrm{t}$ is the very nature of the human condition that each new generation grows into an old world', it cannot be the purpose of education to prepare the new generation for an old world. ${ }^{56}$ Why not? Because this could only mean, and this is important, 'that one wishes to strike from the newcomers' hands their own chance at the new.57 In other words, if the purpose of education were only to socialize the new generation into the (old) orders of society, then the possibility for renewing the world would be lost. So what educational reform concerned with change must do, is to take responsibility for both 'the life and development of the child and for the continuation of the world'.58 This double responsibility for both the welcoming of the new (change) and the living-on of the old (continuation) constitutes a tension in which it is not only the mortal child that needs protection; the world, too, is in need of protection to keep it from being overrun by the new. ${ }^{59}$

The second task for everyone involved in educational reform, then, given the 'language of natality', is to make relational considerations, that is, to keep in tension the relatedness between birth and death, the old and the new, the immortal world and the mortal child, continuation and change. The work to be done, in other words, is relational work since

54 Arendt. "The Crisis", 196.

55 Arendt, "The Crisis", 176.

56 Arendt, "The Crisis", 177.

57 Arendt, "The Crisis", 177.

58 Arendt, "The Crisis", 186 (emphasis added).

59 Arendt, "The Crisis", 186. Let us remind ourselves again that 'the word' for Arendt is not the natural world but the traces of human words and deeds. 
there in birth lies a potentiality to kill and where there in death lies a potentiality for new life. This suggests that birth and death are not worlds apart, as we are made to believe in the 'language of crisis', but that every new beginning necessarily contains an end, and that every end necessarily contains a new beginning. Hence, the temporary interruption of the new suggests that there is no space for the new beginnings unless the old yields, gives in, dies.

\section{c. Educational reform as risk and hope}

The basic situation in which education takes place in the present, for Arendt, is that 'we are always educating for a world that is or is becoming out of joint'. ${ }^{\prime 0}$ Because the world is made by mortal hands it risks wearing out;' she writes, and therefore the fundamental task for every generation is to constantly set the world right anew. ${ }^{61}$ Bringing newness into the world, then, does not sit easily with wanting to enforce change efficiently and smoothly. By contrast, it takes time and is risky work. In contrast to the 'language of crisis' that makes us believe that change can be achieved quickly and once and for all, the work of reform generated from the 'language of natality' demands continuous and constant navigation between different kinds of losses and gains in the knowledge that change always involves the necessary and ever-present risk of destruction.

And yet, the final point to make as to what the notion of natality can offer a language of struggle for education is hope. Arendt writes:

"Our hope always hangs on the new which every generation brings; but precisely because we can base our hope on only this, we destroy everything if we so try to control the new that we, the old, can dictate how it will look."62

Hope in this context, then, is not wishful thinking. Nor is it hope in the 'fait accompli', that is, in what we can predict and already know the answer to. No, the only hope is the new, and to make the new over-live its insertion into the old, we have to refrain from 'killing it' with our already thought out answers and solutions and protect it from being overrun (by the old). This double gesture of distance and proximity is a gesture that, in contrast to control, takes a step back. It implies simply, as Natasha Levinson puts it, that ' $[t]$ he results of efforts are always uncertain'.63 Hoping beyond certainty, then, as a way of initiating educational reform, is about a precarious navigating between a 'no longer' and a 'not yet': between what education can no longer be (identifying a need for change) and what it could become (formulating a vision). The bottom line of this hope is that we are not doomed to subject to a fixed order of things.

60 Arendt. "The Crisis", 192.

61 Arendt. "The Crisis", 192.

62 Arendt. "The Crisis", 192.

63 Natasha Levinson, "The Paradox of Natality: Teaching the Midst of Beleatedness". In Hannah Arendt and Education: Renewing our Common World, (Edited by Mordechai Gordon, Boulder: Westview Press, 2001), 32. 


\section{Conclusion: A Language of Natality for Education}

The work required by the the kind of reform that has the struggle for education close at heart, is that it breaks with automatism and 'one-way-routes' and takes the necessary unpredictability that comes with birth and beginnings seriously. Hence, in contrast to a situation where educational reforms are powerfully and forcefully initiated, often motivated by a one-sided logic that leaves no room for thinking and nuancing, the notion of natality challenges us to think carefully about what needs to be changed, what needs to be preserved, when, why and how.

Drawing on natality and birth as root metaphors for educational reform, however, should not be understood as simply a way to create an oppositional imaginary to the language of crisis'. Rather, it has been the aim of this article to show that the 'language of natality' - as a language of struggle for education - calls for a relationality in thinking and acting that is foreclosed in the violent logic of the 'language of crisis'. This relationality - and this is the gist of the paper - needs to be taken into account when initiating educational change and reform if the new is to over-live the weight of the old.

\section{Acknowledgements}

This article was written by support from School of Culture and Education, Södertörn University, and from the Swedish National Research Council (VR) as part of the research project 'Lived Values: A Pedagogical-Philosophical Groundworking of the Value Basis of Swedish Schools' (2015-2019), diarienummer 721-2014-2200. The author would like to thank the co-editors of this special issue, Marie Hållander and Claudia Schumann, as well as the two anonymous external reviewers for valuable comments. The author would also like to thank Elisabet Langmann, Södertörn University, for valuable feedback on an earlier draft of this paper. 